\title{
An Exploration of the Roles of Certified Child Life Specialists \& Registered Play Therapists in the United States
}

\author{
Julie Lerwick, PhD, LPC, NCC, RPT* \\ University of Western States, USA
}

*Corresponding author: Julie Lerwick, Ph.D., LPC, NCC, RPT, University of Western States, 2900 NE $132 n d$ Avenue, Portland, Oregon 97230, USA, Tel: 503-251-5726

\begin{abstract}
In the United States pediatric hospitals and healthcare organizations are becoming more familiar with the value of Child Life Specialists to partner with children and their families to offer information, preparation, and stress reduction interventions to ease the potential negative emotional impact of a healthcare experience. To that end, Child Life Specialists have a unique role, which is not often understood by other healthcare providers. Historically casually regarded as "the hospital play ladies" Child Life Specialists offer more than simply play. They are child development experts that help to prepare children for unique healthcare experiences. If Child Life Specialists offer therapeutic play to children, what is the role of Registered Play Therapists? This article aims to clarify the roles, training, and scope of practice of both Child Life Specialist and Registered Play Therapists in the United States.
\end{abstract}

\section{Introduction}

Pediatric healthcare was welcomed into the United States in the 1850s when the first children's hospital was established in Philadelphia [1]. Although play has been recognized for centuries as a foundational developmental need for children, the question was posed by early pediatric professionals of how play might be effective in helping children to cope with the assumed stress and trauma related to hospitalization.

Play is a child's natural way of communicating and exploring new experiences. Practitioners and theorists alike agree that play is a necessary aspect of child development. Play is universal and pervasive throughout all cultures, environments, populations and gender. Play is pleasurable. Answering this need to help children through play, by 1950 ten children's hospitals had implemented play programs [2].

Out of this recognition of the healing power of play, two organizations were formed in 1982 to support children in their moments of need: The Child Life Council (CLC) and the Association for Play Therapy (APT). The Child Life Council bestows the credential Certified Child Life Specialist and the Association for Play Therapy bestows the credential Registered Play Therapist. The following paper seeks to explore and clarify the differences between the roles and training of Certified Child Life Specialists and Registered Play Therapists.

\section{Child Life}

In a hospital environment, children are navigating new experiences, questions, emotions, as well as needing structure and normalcy of a non-ill child. With most healthcare professionals focused on the physical health and well being of children, child life specialists seek to meet the emotional and developmental needs of children in healthcare settings. Many children experience hospitalization as stressful, traumatizing and may need support with coping skills.

In 1982, recognizing the need of emotionally supporting children in hospitals, the Child Life Council (CLC) was established to "address the professional", programmatic and educational needs of child life practitioners [3]. Although play and child development experts were part of the hospitalization process back into the early twentieth century, whereby in 1962, Emma Plank wrote of her work with her staff in which she called "child-care workers", there was no formal regulating board to govern the quality standards of the 
child life profession as a whole.

In the Official Documents of the Child Life Council, the mission of child life professionals is to "reduce the negative impact of stressful or traumatic life events and situations that affect the development, health, and well-being of infants, children, youth, and families" ( $p$. 1). Further, they "embrace the value of play as a healing modality as we work to enhance the optimal growth and development of infants, children and youth through assessment, intervention, prevention, advocacy, and education" (p. 1).

Child life specialists are child development experts that are extensively trained to aid in decreasing a child's experience of stress [4] by delivering coping strategies such as education, age-appropriate information, nondirective play, and medical play. Medical play involves inviting children to play out medical procedures in an effort to role-play, explore, and question aspects of their healthcare experience. Substantive research supports the efficacy of child life programs.

\section{Play Therapy}

Originating with roots in humanistic theory and attachment theory, early theorists believed that children demonstrated a form of free-association through their play. Recognizing the foundational expression of play in children and the need to help children heal through their natural way of communicating, in 1982 the Association for Play Therapy (APT) was established with the desire to promote the advancement of play therapy. The APT defines play therapy as "the systematic use of a theoretical model to establish an interpersonal process wherein trained play therapists use the therapeutic powers of play to help clients prevent of resolve psychosocial difficulties and achieve optimal growth and development" [5]. The APT states, "Play therapy should only be provided by mental health professionals who have met the required education, licensure, and additional specialized training and supervision specific to Play Therapy (2018)".

Traditional play is very different from the evidencebased practice of play therapy. It is natural for the two to be confused; yet play therapy is delivered by mental health professionals with extensive training in the modality of play therapy. Play therapy can be used for an array of psychosocial and psychological issue pertaining to children, and even across the lifespan. Developmental theorists believe that play is the primary language that children use to communicate. Play therapy partners with children, through the use of toys, to allow them to unlock sticky emotions and to prevent, resolve, and heal from psychological and emotional struggles in their lives. Play therapy is not simply "playing" with a child. It is a therapeutic method for treating mental and behavioral health issues that can be utilized in any setting, for any issue, with any population.

\section{Education \& License Differences}

Certified Child Life Specialists (CCLS) are required to have a minimum of a Bachelor's degree in any field, with coursework requirements surrounding childdevelopment, play, grief, family systems, and research and child life professional practice. Effective January 2019, in order to be credentialed as a CCLS, you must complete a certification examination as well as a 600-hour internship under the supervision of a CCLS having 4000 hours of paid child life clinical experience [3]. As a pre-requisite, most internship programs also require volunteer and practicum experience, as well. Being that CCLS are not mental health professionals, no mental health license is required. To maintain CCLS certification, the CLC requires an annual Certification Maintenance Fee, but according to their website, no required continuing education.

Registered Play Therapists (RPT) are mental health professionals that hold an active clinical mental health license, which includes state and national examination, and requires a minimum of a master's degree. Coursework includes all clinical mental health training, as well as additional training in child therapy. These additional courses include child development, theories of personality, and principles of psychotherapy, child and adolescent psychopathology, as well as ethics. In addition to completing two years of clinical work, and 2000 hours of supervised clinical experience, and 500 hours of supervised play therapy experience, RPT's complete a minimum of 150 hours of play therapy specific training. Maintaining a state clinical mental health license in good standing and 18 hours of play therapy specific continuing education is required for annual renewal. RPT's are within their scope of practice to assess, diagnose, and treat any mental health condition in children.

\section{Scope of Practice}

Alignment and overlap exists between the two fields of Child Life and Play Therapy. There is a clear beginning and clear ending to each field as it relates to scope of practice, although the differences may not be as transparent as we would like to medical professionals or the general public. As of the time of this writing, Certified Child Life Specialists (CCLS) work in medical settings preparing children for medical procedures and aid in psychological preparation and coping. They are important contributors to the healthcare process for children, families, and professionals alike. Play has been substantiated as medically necessary for children in hospitals. Play gives life and healing to children! Even international studies have shown the importance of play within hospitalization [6]. And in this particular study [6], they have utilized their most common resource - nurses - to deliver the modality of play. They are incorrectly calling it play therapy, but their intent is 
the same. Play has a natural healing element to it and children are benefitting.

But what happens when a child's hospitalization experience causes the onset of anxiety, depression, PTSD? Research in 2007 [7] suggests the need for evaluation of children in the Pediatric Intensive Care Unit (PICU) that are showing PTSD symptomology. This study [7] notes that parents of PICU patients also demonstrate PTSD symptoms. Treating symptoms consistent with DSM-5 criteria of generalized anxiety disorder, major depressive disorder, acute stress disorder, or PTSD must be treated by a licensed clinical mental health professional, such as a Registered Play Therapist (RPT). This is within the scope for assessment, diagnosis, treatment, and prevention.

\section{Recommendations}

Healthcare professionals should seek to clearly understand the difference in the roles and training of Child Life Specialists and Registered Play Therapists. Although it may appear from the outside looking in that both roles are providing therapeutic play, if not play therapy to children, the training is quite different. Moreover, the ethical implications of practicing outside each scope are severe. It is important to identify the role that each professional is fulfilling, as well as being asked to perform. This writer recommends that Child Life Specialist and Registered Play Therapists work together to enhance the delivery of patient care to children in their care. This partnership requires clear understanding of role, training, referral procedures, appropriateness of patient population and most of all scope of practice.

\section{Conflict of Interest}

There is no source of support to disclose and no conflict of interest to disclose.

\section{References}

1. Brodie B (1986) Yesterday, today and tomorrow's pediatric world. Children's Health Care 14: 168-173.

2. Rutkowski J (1986) A survey of child life programs. In: Child life: An overview. ACCH, Washington, USA.

3. Child life council (2011) Official documents of the child life council.

4. Lazarus RS, Folkman S (1984) Stress, appraisal and coping. Springer, New York.

5. (2018) Association for play therapy.

6. Koukourilkos K, Tzeha L, Pantelidou P, Tsalogilidou A (2015) The importance of play during hospitalization of children. Mater Sociomed 27: 438-441.

7. Ward-Begnoche W (2007) Posttraumatic stress symptoms in the pediatric intensive care unit. J Spec Pediatr Nurs 12: 84-92. 